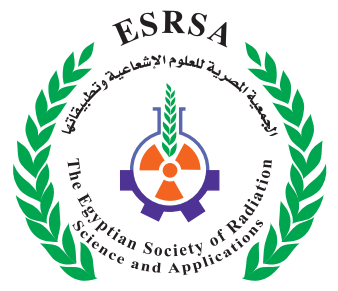

\title{
Fouling Characteristics of MF Membrane Operated for Separation of Nitrocellulose from Wastewater
}

Ismail, A.A. ${ }^{1}$; Abdelaziz, Y.A. ${ }^{2}$ and Giorno, L. $^{3}$

Received: 05/11/2020

Accepted: 11/01/2021

DOI: $10.21608 /$ jntas.2021.48849.1030

E.mail:engyasserali@yahoo.com

\section{ABSTRACT}

Membrane processes for wastewater treatment have become one of the emerging technologies, which affords a fast development through the past few decades. This study investigated the occurrence of fouling membrane and its composition factors and its effect on membrane performance. In this study, a project pilot scale forward the opposition to cluster transport from one side to the other side of membrane is eventual of the membrane and due to the coat of material on the membrane surface and into the membrane. Effect of several parameters including trans-membrane compressing (pressure), crossflow velocity, and organic matter on microfiltration (MF) membrane fouling are investigated. The results show that the organic material existing in the actual wastewater $\mathrm{NC} 30$ does not induce fouling in $0.14 \mu \mathrm{m}$ MF membrane with NC fines.

\section{KEYWORDS}

Inorganic Membrane;

Microfiltration,

Fouling Membrane,

Wastewater.

1. Science \& Technology Center of Excellence, Km.3 Cairo-Belbeis Desert Rd., Cairo, Egypt.

2. Reactors Department, Nuclear Research Center, Atomic Energy Authority, P.O.1375 - Inshas -Egypt.

3. Institute on Membrane Technology, ITM-CNR, Via P. Bucci 17/C, 87030 Rende (CS), Italy. 


\section{INTRODUCTION}

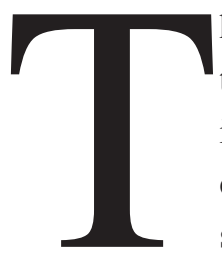

he development of the membrane technologies- has fell far back the initial anticipation, one of the major obstacles which prevent more widespread of its application, is that the filtration performance inevitably decreases with filtration time. This phenomenon is usually termed as membrane fouling, which indicates the blockage of membrane pores during filtration by the collection of sieving and adsorption of particulates and compounds onto the membrane surface or within the membrane pores. Fouling also can be classified, based on the type of fouling material, into four categories as the following: 1- inorganic fouling/scaling, 2- particle/colloidal fouling, 3- microbial/biological fouling, and 4- organic fouling. The first type of fouling (Inorganic fouling or scaling) is caused by the accumulation of particles when the concentration of the chemical species exceeds its saturation concentration. Several studies have shown that increased concentration of $\mathrm{Ca}^{2+}$ and $\mathrm{Mg}^{2+}$ caused more fouling (Hong and Elimelech,1997; Lee et al., 2005; Quintanilla, 2005). Pore blockage of the membrane to reducing the permeate production rate and increasing the complexity of the membrane filtration operation. This is the most challenging issue for developing the membranes applications. Usually, a dominant cake layer of rejected particles usually formed on the membrane surface as a result of the sieving mechanism of the microfiltration. The buildup layer and the clogging of the pores are referred to as the fouling layer. The range to which the membrane fouls depend on the type of membrane and the concentration of contaminants in the feed water (Alvarez, et al., 1996; Baker, 2000).

The total opposition of flux depicted is caused by several factors:

a) Opposition as a result to formation of extremely concentrated layer adjacent to the membrane, concentration polarization, $\mathrm{R}_{\mathrm{cp}}$ " "Which is the ac- cumulation, at the upstream surface of the membrane, of solute molecules that are rejected or retained by the course of ultra- and microfiltration"

b) Opposition as a result to formation of the gel layer, $R_{g}$ due to the increasing the concentration of particles near the surface of the membrane. Resistance to fouling permeate flow is due to poreblocking, $\mathrm{R}_{\mathrm{p}}$, as shown in Fig. (1) (Al-Malack, et al. 1997), Koros (1996).

Membrane resistance, $\left(\mathrm{R}_{\mathrm{m}}=\mathrm{R}_{\mathrm{m}}\right.$ (initial) $+\mathrm{R}_{\mathrm{a}}+$ $R_{p}$ ), may increase with time since $R_{a}$ and $R_{p}$ increase with time of turn on filtration. Resistance due to cake layer is given by $R_{C}=R_{C P}+R_{g}$. Total resistance, $\left(R_{t}=\right.$ $R_{m}+R_{c}$ ), changes with the time of the turn on filtration. The longer the turn on membrane, the harder it is to transfer mass across the membrane. The foulants can be removed and hence the filtration run can be increased using backwashing. Moreover, foulants can undergo irreversible changes to form cohesive stiff which is more difficult to remove. Cardew and his coauthors, noted that concentration polarization forms faster and it is a reversible process, whilst gel polarization is associated with slow irreversible changes and so contributing to more permanent fouling (Cardew et al., 1998).

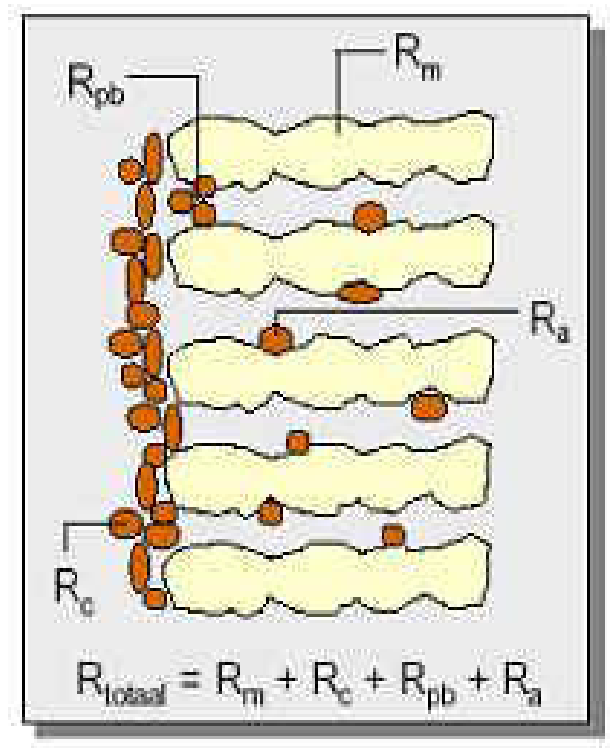

Fig. (1): Resistance due to the formation of membrane fouling. 
c) Membrane resistance, $R_{m}$. depends on some properties of the membrane such as membrane thickness, nominal pore size, pore density/porosity, pore size distribution, pore depth and tortuosity (Ho et al., 1992; Baker et al., 1985).

d) Resistance due to internal colloidal fouling is called $\mathrm{R}_{\mathrm{a}}$.

\section{EXPERIMENTAL INVESTIGATIONS}

\section{Experimental system}

The unit was designed to treat polluted water using MF membrane, to study the contamination of the membranes and the main operating parameters affecting the membrane fouling.

The pilot-scale MF/NF system equipped with stainless-steel housing for tubular inorganic membrane (Rhodia Orelis, Miribel, France) were used. The unit consisted of a 50 L Storage tank made from stainless-steel 316L, air compressor model HAC200/380 Haggar industrial Egypt, feed pump, metal teflon-fitted manufactured by a an American company, equalizer for adapting the entrance of air to diaphragm pump, cartridge filter, digital flow meter manufactured by a Japanese company, centrifugal pump manufactured by a German company (for recirculation of liquid inside membrane module and decreasing the fouling phenomena on the surface of membrane), a tube-in-shell heat exchanger, two pressure transducers $(0-10$ bar) located at the inlet and outlet of the membrane module, temperature sensor and control panel.

\section{Tested Membranes}

Two different tubular inorganic membranes were used (MF, NF) manufactured by (Rhodia Orelis, Miribel, France). The chemical properties, physical properties and geochemical specifications were illustrated in Table (1).

Table (1) : Physical, chemical and geometrical specifications of the Membranes.

\begin{tabular}{|c|c|c|}
\hline Property & MF & NF \\
\hline Membrane material & $\mathrm{ZrO}_{2}$ & $\mathrm{TiO}_{2}-\mathrm{Al}_{2} \mathrm{O}_{3}$ \\
\hline Support & Carbon & Ceramic \\
\hline Configuration: channel tubular & 7 flow & 19 flow \\
\hline Membrane surface area, $\left(\mathrm{m}^{2}\right)$ & 0.16 & 0.245 \\
\hline Operating pressure TMP, $($ bar $)$ & up to 15 & up to 10 \\
\hline Max. operating temperature & up to100 ${ }^{\circ} \mathrm{C}$ & up to $100^{\circ} \mathrm{C}$ \\
\hline pH operating range & $0-14$ & $0-14$ \\
\hline Dimension & $10 \mathrm{~mm}(\mathrm{D}) \times 1200 \mathrm{~mm}$ & $25 \mathrm{~mm}(\mathrm{D}) \times 1178 \mathrm{~mm}$ \\
\hline
\end{tabular}

\section{RESULTS AND DISCUSSION}

This work is concerned with the microfiltration (MF) membrane fouling process, through carrying out a parametric study of the process. Permeate flux and trans-membrane pressure (TMP) is the best indicators of membrane fouling.

\section{Membrane fouling mechanism}

A typical flux-time curve of microfiltration (MF), as shown in Figure (2), starts

With (1) a rapid initial drop of the permeate flux, (2) a long period of gradual flux decrease, and (3) a steady-state flux. 


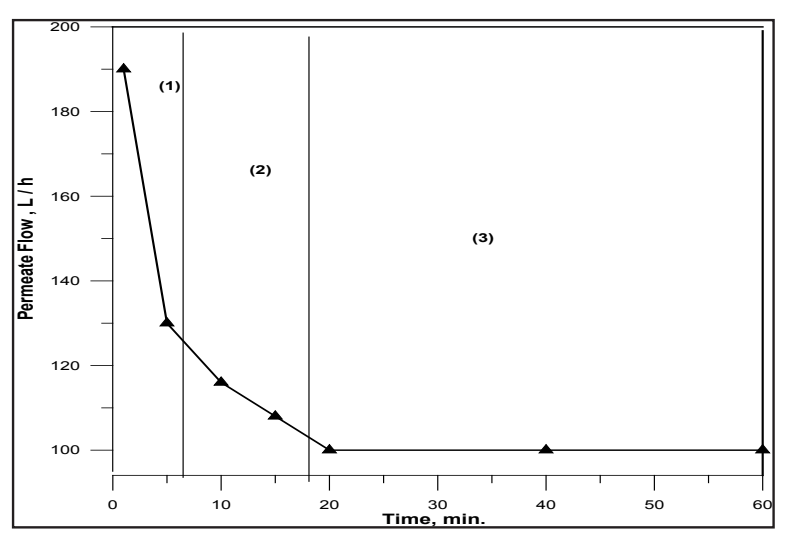

Fig. (2): Decreasing the permeate flow of MF Membrane at removal of NC30 from real wastewater.

(A)

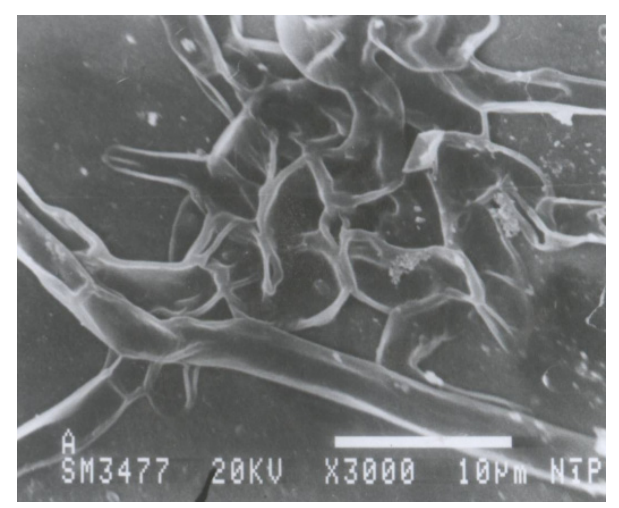

(B)

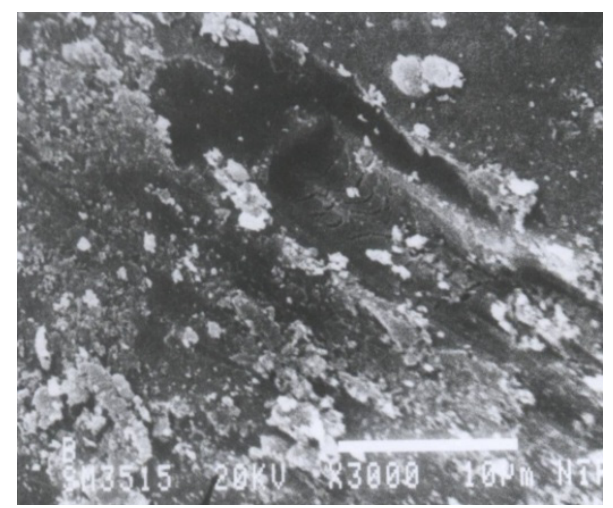

\section{Fouling observations}

The fouled carrbosep membrane was examined using the SEM technique at operating conditions: $\Delta \mathrm{p}, 1 \mathrm{bar}$, cross-flow velocity, $3 \mathrm{~m} / \mathrm{s}$ and temperature $20 \pm 1^{\circ} \mathrm{C}$ ) The $0.14 \mu \mathrm{mMF}$, after filtration of the $\mathrm{NC} 30$ real wastewater. Figure (3) shows virgin 0.14 $\mu \mathrm{m}$ MF carobosep membrane (A) and the fouled membrane (B). It can be seen that the cake layer is composed of densely packed debris of NC fines. The same observation was reported by Byung et al. (1997).
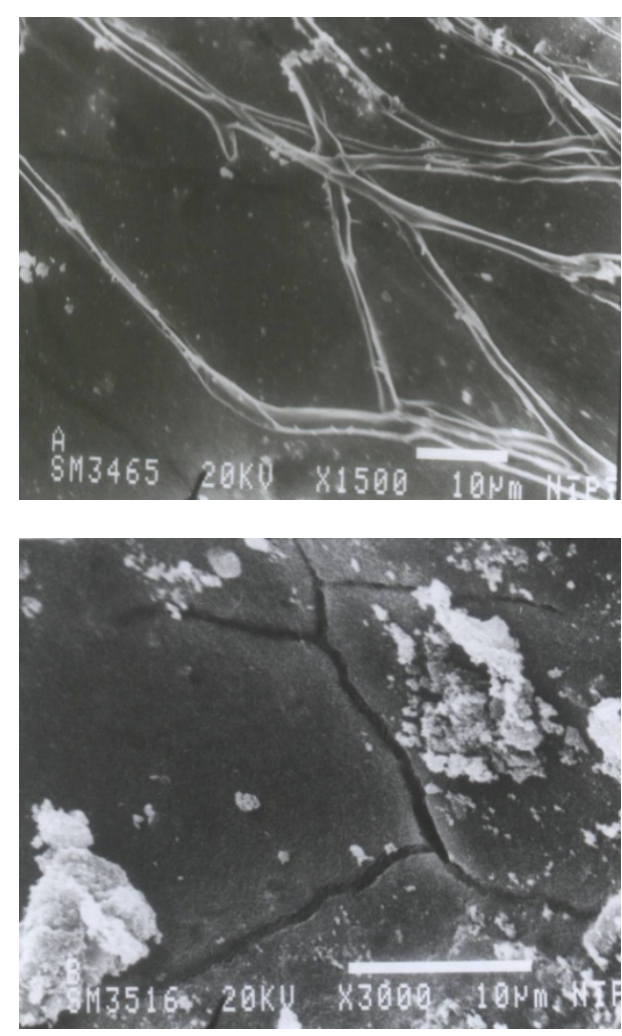

Fig. (3): SEM images of (A) virgin $0.14 \mu \mathrm{m}$ MF membrane, (B) fouled $0.14 \mu \mathrm{m}$ MF membrane.

\section{Effect of organic substance on flux decline}

Fig (4) shows that the $0.14 \mu \mathrm{m}$ MF membrane appears not to be significantly fouled by organic matter, and the flux has never been below 77 percent of the initial flux in the two cases (Real wastewater NC30 and synthetic NC30). The rate of the flux decline is about $18 \%$ of the first permeate flux decline rate during the first $20 \mathrm{~min}$ followed by a relatively slow flux decline rate. A possible explanation is that the molecular sizes of the organic matter in real wastewater NC30 are much smaller than the pore sizes of $0.14 \mu \mathrm{m}$ MF membrane, so most of the organic matter can pass the membrane pores without 
causing severe fouling. To confirm that organic substance present in real wastewater NC30 is not fouling $0.14 \mu \mathrm{m}$ MF membrane with $\mathrm{NC}$ fines. permeates of $0.14 \mu \mathrm{m}$ MF membrane for real wastewater NC30 were collected and analyzed for TSS, turbidity, UV absorbance at $254 \mathrm{~nm}$ (dissolved organic content), at $460 \mathrm{~nm}$ (sum of the coloration and turbidity), at 630 $\mathrm{nm}$ (related to turbidity), TOC and COD. The data are reported in Table (2).

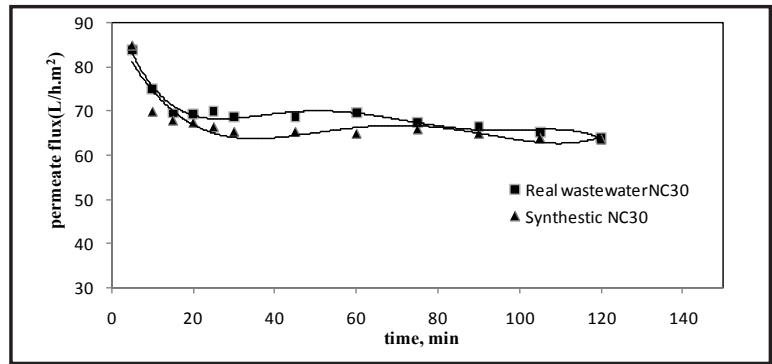

Fig. (4): A comparison between the behaviors of permeate fluxes for Real wastewater NC30 and synthetic NC30 as a function of time for $0.14 \mu \mathrm{m} \mathrm{MF}$.

Table (2): Characteristics of the untreated and treated real NC30 wastewater.

\begin{tabular}{|c|c|c|c|c|}
\hline \multirow{2}{*}{$\begin{array}{c}\text { Parameter } \\
\text { mg/l }\end{array}$} & \multirow{2}{*}{$\begin{array}{c}\text { Untreated } \\
\text { Effluent NC30 }\end{array}$} & \multicolumn{2}{|c|}{$0.14 \mu \mathrm{m}$ MF } & \multirow{2}{*}{$\begin{array}{c}\text { Percentage } \\
\text { rejection, R (\%) }\end{array}$} \\
\hline & & Collected permeate & Retentive at $\mathrm{VRF}=5.9$ & \\
\hline Color & Milky white & Clear & Milky white & \\
\hline $\mathrm{pH}$ & 6.9 & 6.9 & 6.9 & \\
\hline TSS & 367 & 4 & 2178 & 98.9 \\
\hline $\begin{array}{c}\text { Turbidity, } \\
\text { NTU }\end{array}$ & 425 & 1.5 & 2535 & 99.64 \\
\hline TOC & 216 & 205 & 66 & 5.9 \\
\hline COD & 273 & 255 & 120 & 6.5 \\
\hline $\begin{array}{c}\text { Absorb at } \\
254 \mathrm{~nm} \\
430 \mathrm{~nm} \\
630 \mathrm{~nm}\end{array}$ & $\begin{array}{l}1.35 \\
0.61 \\
0.44 \\
\end{array}$ & $\begin{array}{c}1.28 \\
0.025 \\
0.021 \\
\end{array}$ & $\begin{array}{c}0.52 \\
2.8 \\
2.35 \\
\end{array}$ & $\begin{array}{c}5.1 \\
95.9 \\
95.3 \\
\end{array}$ \\
\hline $\mathrm{SO}_{4}^{--}$ & 73 & 71 & 10 & 2.7 \\
\hline NO3 & 6.4 & 5.8 & 4 & 9.3 \\
\hline $\begin{array}{c}\text { Viscosity } \\
\text { (pa.s) }\end{array}$ & $1.037 \times 10^{-3}$ & $1.037 \times 10^{-3}$ & $1.037 \times 10^{-3}$ & \\
\hline
\end{tabular}

\section{Membrane Resistance}

\section{Analysis of resistances of MF membrane}

With a resistance model described by Clark- (1991), ( Laine, et al., 1989), the permeate flux can be expressed as follows:

$J_{o}=\frac{\Delta P}{\mu R_{m}}$

$$
J_{\text {end }}=\frac{\Delta P}{\mu R_{t}}=\frac{\Delta P}{\mu\left(R_{m}+R_{c}+R_{i}\right)}
$$

$J_{f}=\frac{\Delta P}{\mu\left(R_{m}+R_{i}\right)}$

where $J_{o}=$ clean water flux, $J_{\text {end }}=$ flux at the end of each stage, $J_{f}=$ flux after back flush, $\Delta P=$ transmembrane pressure, $\quad=$ dynamic viscosity of per- 
meate, and $R_{t}=$ total resistance, which consists of many components such as intrinsic membrane resistance $\left(R_{m}\right)$, resistance due to reversible cake and/or gel layer $\left(R_{c}\right)$, resistance due to irreversible fouling $\left(R_{i}\right)$. Each resistance component can be calculated from the flux test results.

\section{Effect of trans-membrane pressure on overall resistances of MF experiments}

As filtration proceeds, an NC cake layer begins to be formed and increases the hydraulic resistance against permeates flux in addition to the intrinsic membrane resistance. If the $\mathrm{NC}$ cake resistance is much greater than the intrinsic membrane resistance, the permeate flux will be controlled by the NC cake resistance as filtration proceeds (Byung, et al. 1997).

Fig. (5) shows the measurements of pure water flux for $0.14 \mu \mathrm{m}$ MF carbosep membrane at different stages (before experiment, after the membrane treatment with NC 30, after the membrane back flushing with water and after the membrane cleaning with $1 \%$ $\mathrm{NaOH}$ and $1 \% \mathrm{HNO}_{3}$ ) that were carried out to evaluate the effect of fouling during MF experiments and the possibility of regenerating the membrane.

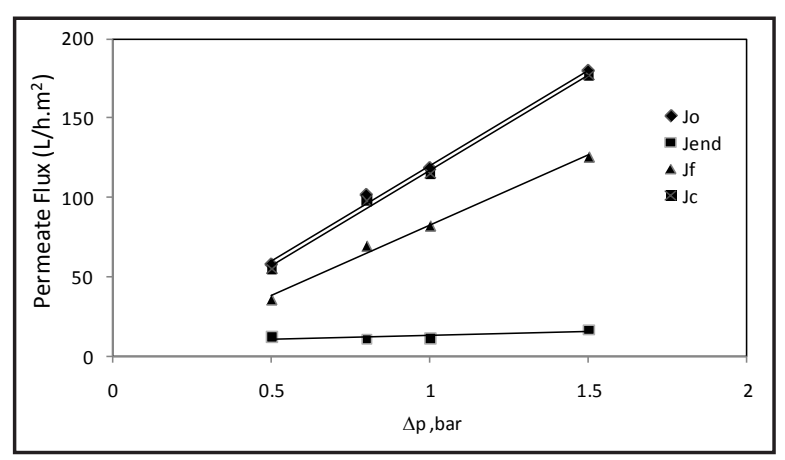

Fig. (5): A comparison of pure water flux through $0.14 \mu \mathrm{m}$ MF membrane,

- Before experiment $\mathrm{J}_{0}$,

- After the membrane treatment with $\underline{\mathbf{N C ~} \mathbf{3 0}} \mathrm{J}_{\text {end }}$,

- After the membrane back flush with water membrane cleaning, $\mathrm{J}_{\mathrm{c}}$

However, Fig. (6), shows the measurements of pure water flux for $0.14 \mu \mathrm{m}$ MF carbosep membrane at different stages (before experiment, after the membrane treatment with $\mathrm{NC} 16$, after the membrane back flushing with water and after the membrane cleaning with $1 \% \mathrm{NaOH}$ and $1 \% \mathrm{HNO}_{3}$ ) that were carried out to evaluate the effect of fouling during MF experiments and the possibility of regenerating the membrane.

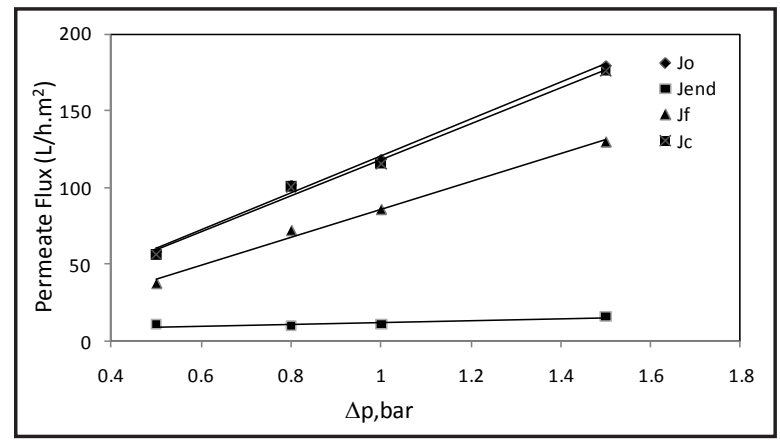

Fig. (6): A comparison of pure water flux through $0.14 \mu \mathrm{m}$

MF membrane,

- Before experiment $\mathrm{J}_{0}$.

- After the membrane treatment with $\underline{\mathrm{NC} 16} \mathrm{~J}$

- After the membrane back flush with water membrane cleaning, $\mathrm{J}_{\mathrm{c}}$.

Figs. (7 and 8) shows the effect of $\Delta \mathrm{P}$ on the overall, fouling and cake layer resistance., with treatment NC30 and NC16 Respectively, these resistances were determined of the steady - state permeates fluxes and the membrane resistance values according to Equations. (3- 1) and (3-2).

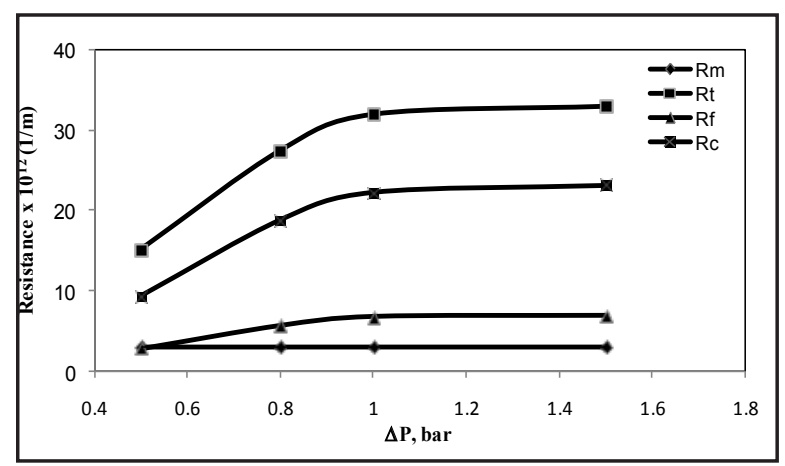

Fig. (7): Influence of $\Delta p$ on total fouling and cake layer ree sistance in the steady-state for $0.14 \mu \mathrm{m} \mathrm{MF}$ (operating conditions, cross-flow velocity $3 \mathrm{~m} / \mathrm{s}$, NC30 feed concentration $200 \mathrm{ppm}$, and $\mathrm{T}=20 \pm 1^{\circ} \mathrm{C}$ ). 


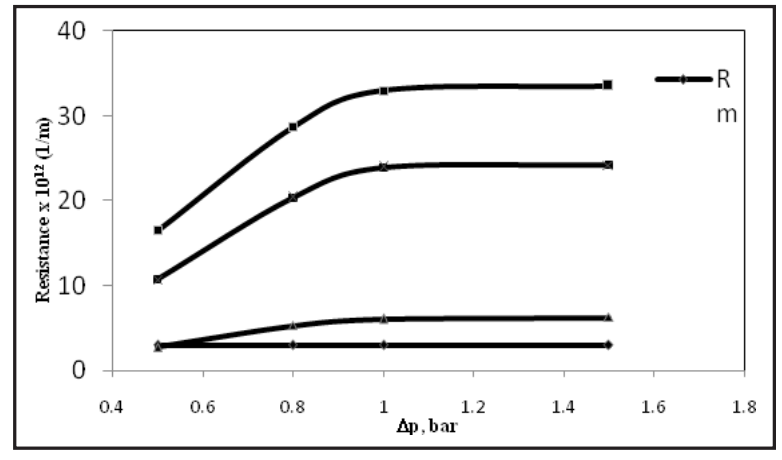

Fig. (8): Influence of $\Delta \mathrm{P}$ on total fouling and cake layer ree sistance in the steady-state for $0.14 \mu \mathrm{m}$ MF (operating conditions, cross-flow velocity $3 \mathrm{~m} / \mathrm{s}$, $\underline{\mathbf{N C 1 6}}$ feed concentration $200 \mathrm{ppm}$ and $\mathrm{T}=20 \pm 1^{\circ} \mathrm{C}$ ).

As shown in these Figures $R_{t}$ increased in the range $0.5-1$ bar then it became independent from further increase in the pressure. $\mathrm{R}_{\mathrm{c}}$ controlled the permeate flux at $\Delta \mathrm{P}$ which is lower than $1 \mathrm{bar}$, while at a higher $\Delta \mathrm{P}$, the permeate flux was controlled by $R_{c}$ and $R_{f}$ which were more than $R_{m}$ over the whole range of the investigated $\Delta \mathrm{P}$. In particular, it decreased with $\Delta \mathrm{P}$ since an increase of pressure enhanced the flux and the connective flow of the solute towards the membrane (mass transfer controlled the membrane system). In Tables (3 and 4) for NC30 and NC16 the percentages of each resistance, at different $\Delta \mathrm{P}$, are reported as follows: only at 0.5 bar $\mathrm{R}_{\mathrm{c}}$ gave the highest contribution to $\mathrm{R}_{\mathrm{t}}$ (about 62\%) for NC30 while NC16 (was about 65\%). This result confirmed the that $\mathrm{NC} 16$ causes a higher reversible and /or irreversible fouling for membrane than that of NC30 due to the larger particle size of NC16 compared to NC30 Allen, (1990), while at higher pressure the most important resistance became $\mathrm{R}_{\mathrm{c}}$ (about $70 \%$ and $72.3 \%$ ) for NC30 and NC16 respectively.

Table (3) : Contribution of $0.14 \mu \mathrm{m}$ MF membrane, fouling and cake layer resistance to the total resistance at different trans membrane pressure for NC 30.

\begin{tabular}{|c|c|c|c|c|c|c|c|c|c|}
\hline $\begin{array}{c}\Delta \mathbf{p}, \\
\mathbf{b a r}\end{array}$ & $\begin{array}{c}\mathbf{R}_{\mathbf{t}}\left(\mathbf{m}^{-1}\right) \\
\mathbf{x} 10^{12}\end{array}$ & $\mathbf{R}_{\mathbf{t}} \%$ & $\begin{array}{c}\mathbf{R}_{\mathbf{m}}\left(\mathbf{m}^{-1}\right) \\
\mathbf{x} 10^{12}\end{array}$ & $\mathbf{R}_{\mathbf{m}} / \mathbf{R}_{\mathbf{t}} \%$ & $\begin{array}{c}\mathbf{R}_{\mathbf{c}}\left(\mathbf{m}^{-1}\right) \\
\mathbf{x} 10^{12}\end{array}$ & $\mathbf{R}_{\mathbf{c}} / \mathbf{R}_{\mathbf{t}} \%$ & $\begin{array}{c}\mathbf{R}_{\mathbf{i}}\left(\mathbf{m}^{-1}\right) \\
\mathbf{x} \mathbf{1 0}^{12}\end{array}$ & $\mathbf{R}_{\mathbf{i}} / \mathbf{R}_{\mathbf{t}} \%$ & $\begin{array}{c}\mathbf{R}_{\mathbf{m}}+\mathbf{R}_{\mathbf{i}} / \\
\mathbf{R}_{\mathbf{t}} \%\end{array}$ \\
\hline 0.5 & 15.15 & 100 & 3 & 19.8 & 9.39 & 62 & 2.82 & 18.2 & 38.42 \\
\hline 0.8 & 27.5 & 100 & 3 & 10.9 & 18.83 & 68.5 & 5.66 & 20.58 & 31.49 \\
\hline 1 & 32 & 100 & 3 & 9.37 & 22.24 & 69.5 & 6.76 & 21.13 & 30.5 \\
\hline 1.5 & 33 & 100 & 3 & 9.09 & 23.1 & 70 & 6.89 & 20.91 & 29.96 \\
\hline
\end{tabular}

Table (4) : Contribution of $0.14 \mu \mathrm{m}$ MF membrane, fouling and cake layer resistance to the total resistance at different trans membrane pressure for NC16.

\begin{tabular}{|c|c|c|c|c|c|c|c|c|c|}
\hline $\begin{array}{c}\Delta \mathbf{p}, \\
\mathbf{b a r}\end{array}$ & $\begin{array}{c}\mathbf{R}_{\mathbf{t}}\left(\mathbf{m}^{-1}\right) \\
\mathbf{\mathbf { 1 } 1 0 ^ { 1 2 }}\end{array}$ & $\mathbf{R}_{\mathbf{t}} \%$ & $\begin{array}{c}\mathbf{R}_{\mathrm{m}}\left(\mathbf{m}^{-1}\right) \\
\mathbf{x} \mathbf{1 0}^{12}\end{array}$ & $\mathbf{R}_{\mathbf{m}} / \mathbf{R}_{\mathbf{t}} \%$ & $\begin{array}{c}\mathbf{R}_{\mathbf{c}}\left(\mathbf{m}^{-1}\right) \\
\mathbf{x} \mathbf{1 0}^{12}\end{array}$ & $\mathbf{R}_{\mathbf{c}} / \mathbf{R}_{\mathbf{t}} \%$ & $\begin{array}{c}\mathbf{R}_{\mathbf{i}}\left(\mathbf{m}^{-1}\right) \\
\mathbf{x} \mathbf{1 0}^{12}\end{array}$ & $\mathbf{R}_{\mathbf{i}} / \mathbf{R}_{\mathbf{t}} \%$ & $\begin{array}{c}\mathbf{R}_{\mathbf{m}}+\mathbf{R}_{\mathbf{i}} / \\
\mathbf{R}_{\mathbf{t}} \%\end{array}$ \\
\hline 0.5 & 16.5 & 100 & 3 & 18.18 & 10.72 & 65 & 2.77 & 16.78 & 34.96 \\
\hline 0.8 & 28.7 & 100 & 3 & 10.45 & 20.37 & 71 & 5.32 & 18.53 & 28.98 \\
\hline 1 & 33 & 100 & 3 & 9.09 & 23.92 & 72.5 & 6.075 & 18.4 & 27.5 \\
\hline 1.5 & 33.5 & 100 & 3 & 8.95 & 24.22 & 72.3 & 6.281 & 18.74 & 27.7 \\
\hline
\end{tabular}




\section{Effect of cross-flow velocity on overall resistances of MF experiments}

As the cross-flow velocity increases, the NC cake layer became denser and more gel-like although it was always reversible (Byung et al., 1997). The positive influence of cross-flow velocity is due to its effect on the diffusion layer and deposit thickness. Its influence would be attributed to its role in the shearing stress Kessler, (1981).

In Figs. (9 and 10), the influence of cross-flow velocity on the total- cake layer and fouling resistance for NC30 and NC16 are shown. It can be seen that $R_{t}$ decreases as the cross-flow velocity increase, showing the same trend of $R_{c}$ since $R_{i}$ remained nearly constant. At a high cross-flow velocity, high shear forces remove the retained material and reduce membrane fouling process efficiency and membrane performance (Alvarez et al., 1996). The contribution of $R_{c}$ to the total resistance in the investigated range of cross-flow velocity remained the most important effect. This result could be explained in relation to the different nature of $\mathrm{NC}$ cake formation on the membrane surface under cross- flow velocity and non-cross-flow velocity conditions. First, the $\mathrm{NC}$ cake layer under cross -flow velocity condition is continuously exposed to a shearing force, and a harsh shearing environment would make the NC cake layer become denser and tighter. Second, the larger NC fines convectively driven onto the cake layer tend to move back into feed stream due to their higher inertia arising from the shear force, and the $\mathrm{NC}$ cake layer would consist of smaller NC fines (Baker et al., (1985). These two phenomena would give a higher resistance of the NC cake layer. (Kim et al., 1993) found a very similar result with colloidal silver particles in the case of stirred filtration which shows a more finely dispersed cake as compared to the case unstirred filtration.

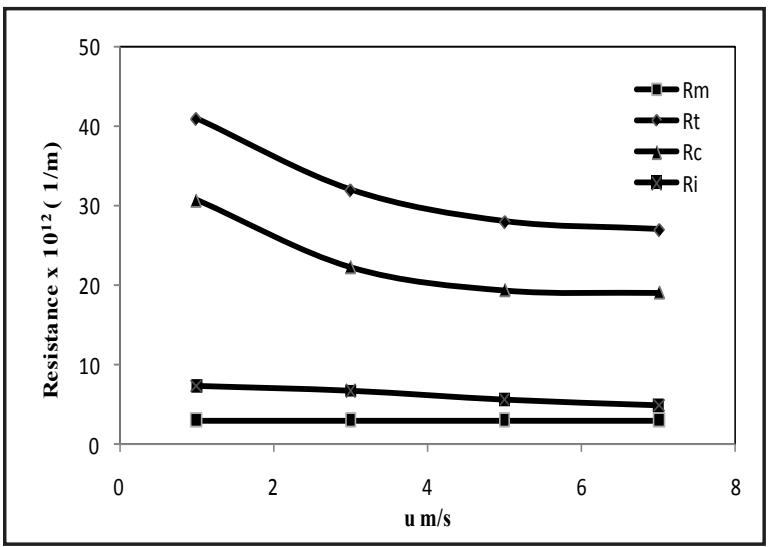

Fig. (9): Effect of cross-flow velocity on the total fouling and cake layer resistance in the steady - state for $0.14 \mu \mathrm{m} \mathrm{MF}$ (operating conditions, $\Delta \mathrm{p}, 1$ bar, $\underline{\mathbf{N C 3 0}}$ feed concentration 200 ppm, and $\mathrm{T}=20 \pm 1^{\circ} \mathrm{C}$ ).

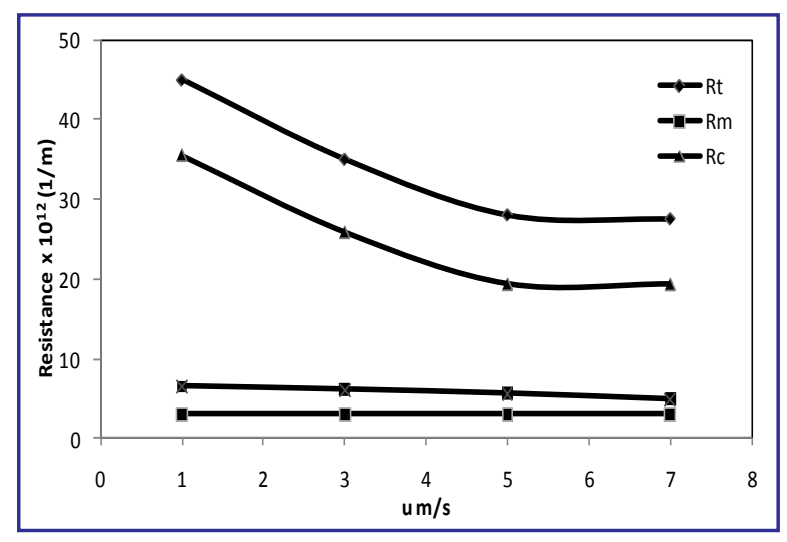

Fig. (10): Effect of cross-flow velocity on the total fouling and cake layer resistance in the steady-state for 0.14 $\mu \mathrm{m}$ MF (operating conditions, $\Delta \mathrm{p}, 1$ bar, $\underline{\mathbf{N C 1 6} \text { feed }}$ concentration $200 \mathrm{ppm}$, and $=20^{\circ} \mathrm{C}$ ).

The permeation over the whole range of crossflow velocity investigated is shown in Tables (5 and 6 ), in which the percentage of each resistance to that of the total resistance are reported. The data show that the contribution of $\mathrm{R}_{c}$ to $\mathrm{R}_{\mathrm{t}}$ is about $70 \%, \mathrm{R}_{\mathrm{i}}$ to $\mathrm{R}_{\mathrm{t}}$ $20 \%$ and $\mathrm{R}_{\mathrm{m}}$ to $\mathrm{R}_{\mathrm{t}} 10 \%$ for $\mathrm{NC} 30$ and $\mathrm{NC} 16$. 
Table (5) : Contribution of $0.14 \mu \mathrm{m} M$ membrane, fouling and cake layer resistance to the total resistance at different cross-flow velocity of NC 30.

\begin{tabular}{|c|c|c|c|c|c|c|c|c|c|}
\hline $\begin{array}{c}\mathbf{U} \\
\mathbf{m} / \mathbf{s}\end{array}$ & $\begin{array}{c}\mathbf{R}_{t}\left(\mathbf{m}^{-1}\right) \\
\mathbf{x} 10^{12}\end{array}$ & $R_{t} \%$ & $\begin{array}{c}\mathbf{R}_{\mathrm{m}}\left(\mathbf{m}^{-1}\right) \\
\mathbf{x} 10^{12}\end{array}$ & $\mathbf{R}_{\mathrm{m}} / \mathbf{R}_{\mathrm{t}} \%$ & $\begin{array}{c}\mathbf{R}_{\mathrm{c}}\left(\mathbf{m}^{-1}\right) \\
\mathbf{x 1 0 ^ { 1 2 }}\end{array}$ & $\mathbf{R}_{c} / \mathbf{R}_{t} \%$ & $\begin{array}{c}\mathbf{R}_{\mathrm{i}}\left(\mathbf{m}^{-1}\right) \\
\mathbf{x} 10^{12}\end{array}$ & $R_{i} / R_{t} \%$ & $\begin{array}{c}\mathbf{R}_{\mathrm{m}}+\mathbf{R}_{\mathrm{i}} / \\
\mathbf{R}_{\mathrm{t}} \%\end{array}$ \\
\hline 1 & 41 & 100 & 3 & 7.31 & 30.7 & 74.87 & 7.3 & 17.8 & 25.12 \\
\hline 3 & 32 & 100 & 3 & 9.37 & 22.3 & 69.68 & 6.7 & 20.93 & 30.31 \\
\hline 5 & 28 & 100 & 3 & 10.71 & 19.4 & 69.28 & 5.6 & 20 & 30.71 \\
\hline 7 & 27 & 100 & 3 & 11.11 & 19.1 & 70.74 & 4.9 & 18.14 & 29.25 \\
\hline
\end{tabular}

Table (6) : Contribution of $0.14 \mu \mathrm{m}$ MF membrane, fouling and cake layer resistance to the total resistance at different cross-flow velocity of NC16.

\begin{tabular}{|c|c|c|c|c|c|c|c|c|c|}
\hline$\underset{\mathbf{m} / \mathbf{s}}{\mathbf{U}}$ & $\begin{array}{r}\mathbf{R}_{\mathbf{t}}\left(\mathbf{m}^{-1}\right) \\
\mathbf{x} 10^{12}\end{array}$ & $\mathbf{R}_{t} \%$ & $\begin{array}{c}\mathbf{R}_{\mathrm{m}}\left(\mathbf{m}^{-1}\right) \\
\mathbf{x} 10^{12}\end{array}$ & $\mathbf{R}_{\mathrm{m}} / \mathbf{R}_{\mathrm{t}} \%$ & $\begin{array}{c}\mathbf{R}_{\mathrm{c}}\left(\mathbf{m}^{-1}\right) \\
\mathbf{x} 10^{12}\end{array}$ & $\mathbf{R}_{c} / \mathbf{R}_{t} \%$ & $\begin{array}{c}\mathbf{R}_{\mathrm{i}}\left(\mathbf{m}^{-1}\right) \\
\mathbf{x} 10^{12}\end{array}$ & $R_{i} / R_{t} \%$ & $\begin{array}{c}\mathbf{R}_{\mathrm{m}}+\mathbf{R}_{\mathrm{i}} / \\
\mathbf{R}_{\mathrm{t}} \%\end{array}$ \\
\hline 1 & 45 & 100 & 3 & 6.66 & 35.5 & 78.88 & 6.5 & 14.44 & 21.12 \\
\hline 3 & 35 & 100 & 3 & 8.57 & 25.88 & 73.94 & 6.1 & 17.42 & 26 \\
\hline 5 & 28 & 100 & 3 & 10.71 & 19.4 & 69.28 & 5.6 & 20 & 30.71 \\
\hline 7 & 27.5 & 100 & 3 & 10.9 & 19.38 & 70.74 & 4.9 & 17.8 & 29.25 \\
\hline
\end{tabular}

\section{CONCLUSIONS}

The flux performance during membrane filtration depends on physicochemical reactivates with the membrane as well as an $\mathrm{NC}$ wastewater characteristic. In implementing membrane process, selecting a proper membrane (membrane type, pore size, and base material) would be the first essential step to minimize reversible and/or irreversible fouling and to enhance the flux performance. Based on the experimental results of the present study, it is concluded that:

- The permeate fluxes gradually decreases as the NC concentration increases until the critical concentration was reached after this no significant improvement in the permeate fluxes was obtained.

- In all experiments of MF, the initial permeate flux of NC16 is slower than the initial permeate flux of NC30. This phenomena can be explained in the light that the membrane fouling mechanism might be due to the diversity in shapes and sizes of NC fines and that the cake layer during filtration will be expected to be more compact and dense (Byung et al., (1997)

- The trans-membrane pressure and cross-flow velocity are the most important operating parameters in membrane filtration process. These factors are directly connected to the cost of the membrane process. One advantage of cross-flow velocity factor is that a shearing effect reduces the cake build up on the membrane surface. As a result, the flux performance is usually expected to increase with the cross-flow velocity since the shearing effect is proportional to cross-flow velocity. 
- The filtration of NC suspension has shown that the main parameter responsible for the decrease in filtrate flux with time is the instantaneous occurrence of fouling. The total resistance $\left(\mathrm{R}_{\mathrm{t}}\right)$ to mass transfer is composed of external and internal fouling resistance $\left(\mathrm{R}_{\mathrm{c}}\right.$ and $\left.\mathrm{R}_{\mathrm{i}}\right)$ and the membrane's own resistance $\left(\mathrm{R}_{\mathrm{m}}\right)$. Thus, the filtrate fluxes variations at operating conditions (cross-flow velocity and trans-membrane pressure) were determined. This helped calculating the various resistances and their respective proportions in the membrane fouling.

- The contribution of cake resistance $\left(\mathrm{R}_{\mathrm{c}}\right)$ to the total resistance $\left(\mathrm{R}_{\mathrm{t}}\right)$ is the main component of fouling: - it represents $50-70 \%$ for MF.

- The contribution of internal fouling resistance $\left(\mathrm{R}_{\mathrm{i}}\right)$ to the total resistance $\left(\mathrm{R}_{\mathrm{t}}\right)$ represents only $10-20 \%$ for $M F ; R_{i}$ increases with the velocity and decreases with the pressure.

- Based on the above results of TOC, UV and COD for the collected permeate; the NC fines are considered a major foulant for carbosep $0.14 \mu \mathrm{m}$ MF membrane.

\section{REFERENCES}

- Hong, S. and Elimelech, M. (1997): Chemical and physical aspects of natural organic matter (NOM) fouling of NF membranes. J. Mem. Sci., 132: 159.

- Lee, S.; Cho, J. and Elimelech, M. (2005): Combined influence of natural organic matter (NOM) and colloidal particles on nano-filtration membrane fouling. J. Mem. Sci., 262: 27.

- Quintanilla, V.A.Y. (2005): Colloidal and non-colloidal NOM fouling of ultra-filtration membranes: analysis of membrane fouling and cleaning. M. Sc. Thesis, UNESCO-IHE

- Alvarez, V.; Andres, L.J.; Riera, F.A. and Alvarez, R. (1996): Microfiltration of apple juice using inorganic membranes: Process optimization and juice stability. Can. J. Chem. Eng., 74: 156.

- Baker, R.W. (2000): Membrane Technology and Application. New York: McGraw-Hill, 2.

- Al-Malack, M.H. and Anderson, G.K. (1997): Use of Cross-flow Microfiltration in Wastewater Treatment. Water Resour., 31(12): 3064.

- Koros (1996): https://www.lenntech.com/membrane-fouling.htm\#ixzz4yDLX4iCO

- Cardew, P.T. and Le, M.S. (1998): Membrane Process: A Technology Guide. Cambridge: The Royal Society of Chemistry, 7.

- Ho, W.S. and Sirkar, K.K. (1992): Membrane handbook. New York: Van Nostrand Reinhold, 457.

- Baker, R.J.; Fane, A.G.; Fell, C.J.D. and Yoo, B.H. (1985): Factors Affecting Flux in Crossflow Filtration. Desalination, 53: 81.

- Byung, J.K.; Mark, M.C. and Lee, Y. (1997): Comparative Evaluation of Ultrafiltration/Microfiltration for removal of nitrocellulose (NC) Fines from Wastewater. USACERL TR 97/116 (USACERL, July 1997).

- Kessler, H.G. (1981): Ultrafillration, Reverse Osmosis, ElecirodiaJvsis in Food Engineering and Dairy Technology, Kessler. Freising.

- Kim, B.J. and Park, J.K. (1993): Comprehensive Evaluation and Development of Treatment Technologies for Nitrocellulose Fines in Process Wastewater. Nitrocellulose Fines Separation and Treatment Workshop Proceedings, November 1993, Purdue University, West Lafayette, IN. 


\section{LIST OF ABBREVIATIONS}

$\begin{array}{ll}\text { NC } & \text { Nitrocellulose } \\ \text { NC30 } & \text { Nitrocellulose for civil application } \\ \text { NC16 } & \text { Nitrocellulose for military application } \\ \mathbf{M F} & \text { Microfiltration } \\ \mathbf{N F} & \text { Naonofiltration } \\ \mathbf{R}_{\mathbf{m}} & \text { Clean membrane resistance }(1 / \mathrm{m}) \\ \mathbf{R}_{\mathbf{a}} & \text { Resistance due to internal colloidal fouling } \\ \mathbf{R}_{\mathrm{cP}} & \text { concentration polarization Resistance }(1 / \mathrm{m}) \\ \mathbf{R}_{\mathbf{c}} & \text { cake Resistance } \\ \mathbf{R}_{\mathbf{t}} & \text { Total Resistance }(1 / \mathrm{m}) \\ \mathbf{R}_{\mathbf{i}} & \text { Internal fouling resistance }(1 / \mathrm{m}) \\ \Delta \mathbf{P} & \text { Transmembrane pressure }(\mathrm{bar}) \\ \mathbf{J}_{\mathbf{0}} & \text { initial permeate flux of distilled water }\left(\mathrm{L} / \mathrm{m}^{2}-\mathrm{hr}\right) \\ \mathbf{J} & \text { volumetric flux }\left(\mathrm{L} / \mathrm{m}^{2}-\mathrm{hr}\right) \\ \mathbf{F R} & \text { flux reduction } \\ \mathbf{A}_{\mathbf{m}} & \left.\text { Area of the membrane (m }{ }^{2}\right) \\ \mathbf{V} & \text { volume of the permeate }(\mathrm{L}) \\ \mathbf{t} & \text { time(s) } \\ \Delta \mathbf{X}_{\mathbf{m}} & \text { membrane thickness (m) } \\ u & \left.\text { Tangential velocity (ms }{ }^{-1}\right) \\ \mathbf{T O C} & \text { Total organic carbon analyzer } \\ & \end{array}$

